BMJ Open Sport \& Exercise Medicine

\title{
Side effects of and contraindications for whole-body electro-myo-stimulation: a viewpoint
}

Claudia Stöllberger (D), Josef Finsterer

To cite: Stöllberger C, Finsterer J. Side effects of and contraindications for whole-body electro-myostimulation: a viewpoint. $B M J$ Open Sport \& Exercise Medicine 2019;5:e000619. doi:10.1136/ bmjsem-2019-000619

\section{Check for updates}

(C) Author(s) (or their employer(s)) 2019. Re-use permitted under CC BY-NC. No commercial re-use. See rights and permissions. Published by BMJ.

KA Rudolfstiftung, Wien, Austria

Correspondence to Dr Claudia Stöllberger; claudia.stoellberger@chello.at

\section{ABSTRACT}

Whole-body electro-myo-stimulation (WB-EMS) has been introduced as an alternative to physical training. Data about side effects and contraindications of WB-EMS are summarised. From healthy subjects, elevation of creatinekinase (CK) activity with inter-individual variability was reported after WB-EMS. No data about applied current types, stimulation frequency and risk factors were given. In randomised trials investigating WB-EMS, CK activity was not measured. Seven cases of rhabdomyolysis after WB-EMS were found, and it remains open whether WBEMS was the only risk factor. In healthy subjects, WBEMS does not seem to affect blood pressure, heart rate and oxygen uptake. The lists of exclusion criteria are, in part, contradictory between different studies, especially regarding malignancy and heart failure. Risk factors for rhabdomyolysis are not mentioned as contraindications for WB-EMS. Scientific research should concentrate on muscle damage as a side effect of WB-EMS considering current types applied, stimulation frequency and risk factors for rhabdomyolysis. Research about WB-EMS should include longitudinal muscle force measurements and MRI. Subjects, intending to perform WB-EMS, should undergo investigations by a physician comprising a screen for risk factors for rhabdomyolysis. The education of operators working in gyms with WB-EMS should be regulated and improved. Regulatory authorities should become aware of the problem. Those working in the field should start an initiative on an international level to increase the safety of WB-EMS.

\section{INTRODUCTION}

Whole-body electro-myo-stimulation (WBEMS) is used as a complement to voluntary exercise in athletes, for improving fitness and health in healthy subjects and in patients who cannot perform conventional voluntary exercise because of illness. ${ }^{1-8}$

It has been shown, however, that singlemuscle EMS induces muscular damage which manifests with muscle force reduction up to $-20 \% 4$ respectively 7 days afterwards. ${ }^{9} 10$ Additionally, findings from MRI suggest that tissues other than muscles, such as connective tissues and/or intracellular structures could be altered during single-muscle EMS-induced contractions. ${ }^{10}$
The evidence that WB-EMS is more effective than conventional training for increasing muscle force or mass is lacking. The effectiveness of WB-EMS has been recently questioned by a meta-analysis. ${ }^{11}$ Despite these scientific concerns, manufacturers claim WB-EMS as useful for increasing strength, losing fat or improving general health. ${ }^{11}$ WB-EMS is offered by fitness centres and WB-EMSdevices are available for purchase in shops and the internet.

The potential of WB-EMS to trigger rhabdomyolysis has created concerns. ${ }^{12-14}$ WB-EMS is contraindicated in patients with implanted electronic devices. Apart from these contraindications, there is a lack of universally accepted contraindications. Aim of the article is to summarise data about side effects and contraindications and to develop suggestions how to improve the safety of WB-EMS.

\section{METHODS}

The literature was searched out using the terms 'whole-body electro-myo-stimulation' or 'whole-body EMS' in PubMed from 2000 to October 2019. For side effects and contraindications, we combined the terms with 'side effects', 'rhabdomyolysis' or 'contraindications'. Excluded were articles about patients with cerebral diseases or local muscular problems, in vitro studies and animal experiments. Considered were articles in English and German language. Randomised clinical trials, subgroup analyses from randomised trials, longitudinal studies, case series and case reports were included. Both authors independently screened the titles and abstracts, identified articles of interest and read them in full text.

\section{RESULTS}

Muscular damage by WB-EMS in healthy humans The technique of WB-EMS, indications and how it may induce muscular damage has been summarised. ${ }^{15}$ Muscular damage, assessed by elevation of serum creatine-kinase (CK) 


\begin{tabular}{lll}
\hline Table 1 & CK activity after WB-EMS & \\
\hline Author & Subjects & CK activity \\
\hline 1 & Professional male soccer players $(\mathrm{n}=22)$ & $\begin{array}{l}\text { Pre-WB-EMS } 530.30 \pm 230.00 \mathrm{IU} / \mathrm{L}, \\
24 \text { hours post-WB-EMS } 1,199.89 \pm 569.69 \mathrm{IU} / \mathrm{L}\end{array}$ \\
& & 24 hours after WB-EMS a mean increase in 250 IU, maximum \\
2 & Heart failure patients $(\mathrm{f}=4, \mathrm{~m}=11)$ & $2779 \mathrm{IU} / \mathrm{L}$ \\
& & $\begin{array}{l}\text { Mean 2.9-fold increase from baseline to } 8 \text { weeks of WB-EMS } \\
(\mathrm{p}=0.002)\end{array}$ \\
& Advanced solid tumour patients $(\mathrm{f}=3, \mathrm{~m}=11)$ & Increase peaking at 96 hours post-exercise (mean 28545IU/L)
\end{tabular}

CK, creatine kinase; f, females; m, males; n, Number of subjects; WB-EMS, whole-body electro-myo-stimulation.

activity, has been reported after WB-EMS, as listed in table $1 .{ }^{12816} \mathrm{CK}$ activity rose continuously until the last measurement. The last measurements were carried out 96 hours after WB-EMS and no information is available, at which time CK activities declined. One of these studies found that after 10 weeks of WB-EMS (one session/week), CK reaction was significantly blunted $(906 \pm 500 \mathrm{IU} / \mathrm{L}){ }^{16}$

From these studies, only the mean values were reported and not individual data. Females were under-represented. No explanation is given for the high inter-individual variability of CK activity after WB-EMS.

\section{WB-EMS in patients with heart failure}

Regular aerobic exercise is recommended for patients with heart failure as class I evidence level A. ${ }^{17}$ WB-EMS is discussed as an alternative for physical training in these patients. A pilot study in 15 patients with heart failure investigated the impact of WB-EMS during 6 months on peak oxygen uptake, blood pressure and muscle volume. ${ }^{2}$ CK activity increased by $250 \mathrm{U} / \mathrm{L}$, in single cases up to $2770 \mathrm{U} / \mathrm{L}^{2}{ }^{2}$ A non-randomised study in 34 patients with heart failure applied WB-EMS for 10 weeks twice weekly for $20 \mathrm{~min}$. No CK-levels are reported. ${ }^{3}$

\section{WB-EMS in elderly patients with sarcopenic obesity}

Many elderly people do not reach the recommended exercise doses. WB-EMS has been investigated as an intervention in randomised trials. ${ }^{4-6}$ WB-EMS improved metabolic indices of uncertain clinical relevance. Measurement of CK activity was not carried out. Several patients suffered from 'discomfort' during and 'muscle soreness' after WB-EMS, but no details are given. ${ }^{4-6}$

\section{WB-EMS in patients with advanced cancer}

In a non-randomised trial, 131 patients with advanced solid tumours undergoing anti-cancer therapy were allocated to a control group $(n=35)$ receiving individualised nutritional support or to an intervention group $(n=96)$ that additionally performed WB-EMS $2 \times /$ week for 12 weeks. ${ }^{8}$ No patient withdrew from the study due to discomfort or adverse events related to the WB-EMS training. In a subgroup of 13 patients from this study, CK activity was assessed and ranged from 39 to $1130 \mathrm{IU} / \mathrm{L}$ in week $4 .^{8}$

\section{Rhabdomyolysis after WB-EMS}

Rhabdomyolysis is a potentially life-threatening condition. Although consensus criteria for rhabdomyolysis are lacking, a reasonable definition is elevation of serum CK activities of at least 10 times the upper limit of normal. ${ }^{18}$ Rhabdomyolysis is characterised by the rupture and necrosis of muscle fibres, resulting in release of cell degradation products and intracellular elements within the bloodstream and extracellular space. In $60 \%$, there are two or more causative factors (tables 2 and 3). ${ }^{18} 19$ The classic symptoms of rhabdomyolysis-muscle pain, weakness and dark urine-are observed in only $10 \%$. Up to $50 \%$ only complain about non-specific symptoms such as fever, general malaise, tachycardia, nausea and vomiting. 19

Our research disclosed seven cases of rhabdomyolysis after WB-EMS. ${ }^{13}$ 20-23 In most of the cases, rhabdomyolysis occurred after the first WB-EMS. Renal affection was found in several patients, dialysis was not necessary. Rhabdomyolysis after WB-EMS has not only been reported in untrained individuals but also in two highly trained professional soccer players. ${ }^{21}$

It is unclear if the reported seven cases developed rhabdomyolysis only because of WB-EMS, or whether they took drugs which they did not report, if they had previous infections, where dehydrated, or whether they carried out additional exercise. Rhabdomyolysis after WB-EMS may be favoured by clinically silent or oligosymptomatic myopathies, as speculated in three of the seven cases. ${ }^{20} 22$ None of the studies about CK elevations after WB-EMS (table 1) looked for comorbidities and medications favouring rhabdomyolysis (tables 2 and 3).

Possibly, the number of unreported cases of rhabdomyolysis after WB-EMS is high, since the classical symptoms of rhabdomyolysis are only found in $10 \%{ }^{19}$

\section{Other side effects of WB-EMS}

Heart rate, systolic and diastolic blood pressure, and oxygen uptake were investigated in 68 healthy subjects, randomised to physical exercise combined with or without WB-EMS. After a 6-week training period, the findings did not differ between both groups. ${ }^{7}$ In 117 advanced cancer patients, red and white cell count, serum creatinine, albumin and C-reactive protein (CRP) concentration did 
Table 2 Causes of rhabdomyolysis (according to Zutt et $a l^{18}$ )

\section{Acquired}

Non-traumatic, non- Alcohol/drug abuse ${ }^{*}$ exertional

Medication*

Toxic agents

Anaesthetics and neuromuscular

blocking agents

Infections

Electrolyte disturbances

Endocrine disorders

Inflammatory myopathies

Temperature extremes

Muscle ischaemia

Neuroleptic malignant syndrome

Non-traumatic, Extreme physical exertion

exertional

\begin{tabular}{|c|c|}
\hline & Sickle cell crisis \\
\hline & Status epilepticus \\
\hline & Hyperkinetic syndrome \\
\hline & Status asthmaticus \\
\hline Traumatic & Multiple injuries \\
\hline & Crush injury \\
\hline & Electrical injury \\
\hline & Extensive burns \\
\hline & Vascular/orthopaedic surgery \\
\hline & Prolonged immobility \\
\hline Genetic & \\
\hline Inborn errors of & Glycolysis/glycogenolysis \\
\hline & Lipid metabolism \\
\hline & Krebs cycle \\
\hline & Purin nucleotide cycle \\
\hline & Mitochondrial respiratory chain \\
\hline & Mitochondrial tRNA \\
\hline Myopathies & \\
\hline & Muscular dystrophies \\
\hline & Miyoshi myopathy \\
\hline & Fukutin-related proteinopathy \\
\hline & $\begin{array}{l}\text { Malignant hyperthermia due } \\
\text { to ryanodine receptor type } 1 \\
\text { mutations. }\end{array}$ \\
\hline
\end{tabular}

${ }^{*}$ For details see table 3.

not differ between patients randomised to WB-EMS and controls. $^{8}$

Contraindications for WB-EMS

WB-EMS is contraindicated in patients with implanted electronic devices such as pacemakers, implanted
Table 3 Drugs that have been associated with rhabdomyolysis (according to Cervellin et $a l^{19}$ )

\section{Antipsychotics and antidepressants}

\begin{tabular}{|c|c|}
\hline & Amitriptyline \\
\hline & Amoxapine \\
\hline & Chlorpromazine \\
\hline & Doxepin \\
\hline & Fluphenazine \\
\hline & Fluoxetine \\
\hline & Haloperidol \\
\hline & Lithium \\
\hline & Olanzapine \\
\hline & Protriptyline \\
\hline & Perphenazine \\
\hline & Promethazine \\
\hline & Risperidone \\
\hline & Trifluoperazine \\
\hline Abuse substances & Alcohol \\
\hline & $\begin{array}{l}\text { Amphetamine/methamphetamine } \\
\text { (MDMA, ecstasy) }\end{array}$ \\
\hline & Caffeine \\
\hline & Cocaine \\
\hline & Heroin \\
\hline & Lysergic acid diethylamide (LSD) \\
\hline & Mephedrone \\
\hline & Methadone \\
\hline & Phencyclidine \\
\hline & Synthetic cannabinoids \\
\hline & Toluene \\
\hline $\begin{array}{l}\text { Hypnotics and } \\
\text { sedatives }\end{array}$ & Diazepam \\
\hline
\end{tabular}

sedatives

\begin{tabular}{ll} 
& Nitrazepam \\
& Flunitrazepam \\
& Lorazepam \\
& Propofol \\
& Triazolam \\
& Barbiturates \\
\hline Antihistamines & Diphenhydramine \\
\hline Anti-hyperlipidemic & Doxylamine \\
agents & Lovastatin \\
\hline & Pravastatin \\
\hline & Simvastatin \\
& Fluvastatin \\
\hline & Atorvastatin \\
\hline & Rosuvastatin \\
\hline & Clofibrate \\
\hline & Bezafibrate \\
\hline
\end{tabular}

Continued 
Table 3 Continued

\begin{tabular}{ll}
\hline Antipsychotics and antidepressants \\
\hline & Fenofibrate \\
\hline $\begin{array}{l}\text { Other medicines: } \\
\text { miscellaneous }\end{array}$ & Amphotericin B \\
& Azathioprine \\
\hline & Corticosteroids \\
& Colchicine \\
\hline & Epsilon-aminocaproic acid \\
& Fluoroquinolones \\
& Halothane \\
& Macrolides \\
& Methanol \\
& Moxalactam \\
& Oxprenolol \\
& Paracetamol \\
& Penicillamine \\
\hline Pentamidine \\
\hline Phenylpropanolamine \\
\hline Quinidine \\
\hline Salicylates \\
Succinylcholine \\
Theophylline \\
\hline Terbutaline \\
Thiazides \\
Trimethoprim-sulfamethoxazole \\
Vasopressin \\
\hline
\end{tabular}

MDMA, Methylen-Dioxy-Methyl-Amphetamin.

defibrillators, neuro-stimulators or pain pumps because of potential electrical interference. There are various diseases or conditions mentioned as exclusion criteria, as listed in table 4. Some contraindications are contradictory: malignancy or heart failure is listed as contraindications, ${ }^{37}$ whereas other studies concentrated on patients with these diseases. ${ }^{2}{ }^{8}$ Surprisingly, prior rhabdomyolysis, a history of muscle cramps and potential causes for rhabdomyolysis (as listed in tables 2 and 3 ) are not mentioned as contraindication.

We did not detect any reports about complications of WB-EMS associated with the disorders mentioned in table 4. Thus, it remains unclear on which data and considerations these contraindications were based.

Many patients with heart failure receive electronic devices to protect against sudden cardiac death or to improve systolic function. ${ }^{17}$ WB-EMS is feasible in patients with heart failure. ${ }^{2}$ Thus, it should be investigated, if implanted electronic devices and cardiac diseases are indeed contraindications for WB-EMS.
Table 4 Disorders, listed as exclusion criteria for patients in WB-EMS trials

\begin{tabular}{|c|c|}
\hline Disorder & Reference \\
\hline Implanted electronic devices & $\begin{array}{l}\text { All WB-EMS } \\
\text { trials }\end{array}$ \\
\hline Endoprosthesis, any internal metallic materials & 578 \\
\hline Cardiac decompensation in the past 3 months & 23 \\
\hline NYHA class IV & 23 \\
\hline Left ventricular ejection fraction $<25 \%$ & 3 \\
\hline Left ventricular ejection fraction $<20 \%$ & 2 \\
\hline Severe cardiac arrhythmias & 3 \\
\hline Cardiac arrhythmia Lown IV & 2 \\
\hline Cardiac arrhythmia & 56 \\
\hline Relevant valve stenosis or regurgitation (degree $>$ mild) & 23 \\
\hline Myocardial infarction in the past 3 weeks & 2 \\
\hline Unstable angina & 2 \\
\hline Any history of coronary arterial disease & 7 \\
\hline Active myocarditis & 23 \\
\hline Hypertrophic cardiomyopathy & 23 \\
\hline Pregnancy & 238 \\
\hline Epilepsy & 6 \\
\hline Renal insufficiency & 5 \\
\hline Kidney dysfunction (creatinine $>1.5 \mathrm{mg} / \mathrm{dL}$ ) & 3 \\
\hline Alcohol consumption $>80 \mathrm{~g} / \mathrm{d}$ on 5 days $/$ week & 4 \\
\hline Any history of cerebrovascular disease & 78 \\
\hline Severe cerebral trauma & 7 \\
\hline Impairment of a major organ system & 7 \\
\hline Severe lung disease & 7 \\
\hline Uncontrolled hypertension & 7 \\
\hline Cancer & 7 \\
\hline Psychiatric diseases & 7 \\
\hline Abdomen/groin hernia & 6 \\
\hline Extensive dermatologic disorders & 28 \\
\hline Thrombosis & 8 \\
\hline Intake of anabolic drugs & 8 \\
\hline Severe neurological diseases & 8 \\
\hline Oncological surgery in the last 3 months & 8 \\
\hline
\end{tabular}

NYHA, New York Heart Association; WB-EMS, whole-body electromyo-stimulation.

\section{Precautions for WB-EMS}

Regulations and guidelines regarding WB-EMS were found only for Germany and Israel. ${ }^{12} 14$

The German guideline recommends that before the first training session, a history of possible contraindications must be taken. WB-EMS must be advised and accompanied by a trained WB-EMS-coach. Additionally, fluids should be consumed before and after training. After initial WB-EMS, the stimulation level should be successively increased. The guideline generally advises against private use of WB-EMS without support of a qualified and licensed trainer. ${ }^{12}$ It is not indicated, however, 
where the list of contraindications is available, who should take the history and what is a 'licensed' trainer.

In Israel, the Ministry of Health issued regulations. ${ }^{14}$ All WB-EMS devices have to be registered either as medical device or as device for physical training. The operator has to be a qualified fitness gym coach with a training of at least 30 hours. $^{14}$

\section{CONCLUSION}

To increase knowledge on the potential risks and effects of WB-EMS, we propose the following research priorities: Research about muscle damage as a side effect of WB-EMS should consider current types applied, stimulation frequency and risk factors for rhabdomyolysis. Research about WB-EMS should include longitudinal muscle force measurements, the best indirect marker of muscle damage. ${ }^{9}$ Side effects of WB-EMS on other organ systems should be investigated, also by applying MRI which has been, so far, only applied in single-muscle EMS. ${ }^{10}$ The list of contraindications should be modified according to the results of the above-mentioned research.

Regarding practical aspects, we suggest that subjects intending to perform WB-EMS should undergo investigations by a physician who is a specialist in sports or internal medicine. This investigation should comprise a screening for risk factors for rhabdomyolysis. If there are indications for a myopathy, a neurological examination should be carried out. The education of operators working in gyms with WB-EMS should be organised, in a similar way like in Israel. ${ }^{14}$

There is an urgent need that regulatory authorities become aware of the problem. Those working in the field should start an initiative on an international level to increase the safety of WB-EMS.

Contributors Both authors have contributed equally to (1) conception and design, acquisition, analysis and interpretation of data; (2) drafting the article and revising it critically for important intellectual content and (3) final approval of the version to be submitted.

Funding The authors have not declared a specific grant for this research from any funding agency in the public, commercial or not-for-profit sectors.

Competing interests None declared.

Patient consent for publication Not required.

Provenance and peer review Not commissioned; externally peer reviewed.

Open access This is an open access article distributed in accordance with the Creative Commons Attribution Non Commercial (CC BY-NC 4.0) license, which permits others to distribute, remix, adapt, build upon this work non-commercially, and license their derivative works on different terms, provided the original work is properly cited, appropriate credit is given, any changes made indicated, and the use is non-commercial. See: http://creativecommons.org/licenses/by-nc/4.0/.

ORCID iD

Claudia Stölllberger http://orcid.org/0000-0001-7335-3120

\section{REFERENCES}

1 Filipovic A, Grau M, Kleinöder $\mathrm{H}$, et al. Effects of a whole-body electrostimulation program on strength, sprinting, jumping, and kicking capacity in elite soccer players. $J$ Sports Sci Med 2016;15:639-48.

2 Fritzsche D, Fruend A, Schenk S, et al. [Electromyostimulation (EMS) in cardiac patients. Will EMS training be helpful in secondary prevention?]. Herz 2010;35:34-40.

3 van Buuren F, Mellwig KP, Prinz C, et al. Electrical myostimulation improves left ventricular function and peak oxygen consumption in patients with chronic heart failure: results from the exEMS study comparing different stimulation strategies. Clin Res Cardiol 2013;102:523-34.

4 Kemmler W, Kohl M, Freiberger E, et al. Effect of whole-body electromyostimulation and / or protein supplementation on obesity and cardiometabolic risk in older men with sarcopenic obesity: the randomized controlled FranSO trial. BMC Geriatr 2018;18:70.

5 Kemmler W, Teschler M, Weissenfels A, et al. Whole-Body electromyostimulation to fight sarcopenic obesity in communitydwelling older women at risk. Resultsof the randomized controlled FORMOsA-sarcopenic obesity study. Osteoporos Int 2016;27:3261-70.

6 Kemmler W, Bebenek M, Engelke K, et al. Impact of whole-body electromyostimulation on body composition in elderly women at risk for sarcopenia: the training and electrostimulation trial (TEST-III). Age 2014;36:395-406.

7 Jee Y-S. The efficacy and safety of whole-body electromyostimulation in applying to human body: based from graded exercise test. J Exerc Rehabil 2018;14:49-57.

8 Schink K, Herrmann HJ, Schwappacher R, et al. Effects of wholebody electromyostimulation combined with individualized nutritional support on body composition in patients with advanced cancer: a controlled pilot trial. BMC Cancer 2018;18:886.

9 Fouré A, Le Troter A, Ogier AC, et al. Spatial difference can occur between activated and damaged muscle areas following electricallyinduced isometric contractions. J Physiol 2019;597:4227-36.

10 Jubeau M, Muthalib M, Millet GY, et al. Comparison in muscle damage between maximal voluntary and electrically evoked isometric contractions of the elbow flexors. Eur J Appl Physiol 2012;112:429-38.

11 Pano-Rodriguez A, Beltran-Garrido JV, Hernández-González V, et al. Effects of whole-body ELECTROMYOSTIMULATION on health and performance: a systematic review. BMC Complement Altern Med 2019;19:87.

12 Kemmler W, Froehlich M, von Stengel S, et al. Whole-Body Electromyostimulation - the need for common sense! rationale and guideline for a safe and effective training. Dtsch Z Sportmed 2016;2016:218-21.

13 Malnick SDH, Band Y, Alin P, et al. It's time to regulate the use of whole body electrical stimulation. BMJ 2016;352:i1693.

14 News and Events. Available: https://www.health.gov.il/English/ News_and_Events/Spokespersons_Messages/Pages/11022016_1. aspx [Accessed 9 Dec 2017].

15 Stöllberger C, Finsterer J. Side effects of whole-body electro-myostimulation. Wien Med Wochenschr 2019;169:173-80.

16 Kemmler W, Teschler M, Bebenek M, et al. [(Very) high Creatinkinase concentration after exertional whole-body electromyostimulation application: health risks and longitudinal adaptations]. Wien Med Wochenschr 2015;165:427-35.

17 Ponikowski P, Voors AA, Anker SD, et al. ESC Guidelines for the diagnosis and treatment of acute and chronic heart failure: The Task Force for the diagnosis and treatment of acute and chronic heart failure of the European Society of Cardiology (ESC)Developed with the special contribution of the Heart Failure Association (HFA) of the ESC. Eur Heart J 2016;2016:2129-200.

18 Zutt R, van der Kooi AJ, Linthorst GE, et al. Rhabdomyolysis: review of the literature. Neuromuscul Disord 2014;24:651-9.

19 Cervellin G, Comelli I, Benatti M, et al. Non-Traumatic rhabdomyolysis: background, laboratory features, and acute clinical management. Clin Biochem 2017;50:656-62.

20 Herzog A, Büchele F, Keller DI. Muskelschmerzen nACh Elektromyostimulationstraining. Praxis 2017;106:1121-4.

21 Kästner A, Braun M, Meyer T. Two cases of rhabdomyolysis after training with electromyostimulation by 2 young male professional soccer players. Clin J Sport Med 2015;25:e71-3.

22 Finsterer J, Stöllberger C. Severe rhabdomyolysis after MIHAbodytec ${ }^{\circledR}$ electrostimulation with previous mild hyper-CK-emia and noncompaction. Int J Cardiol 2015;180:100-2.

23 Hong JY, Hyeok Oh J, Shin J-H. Rhabdomyolysis caused by knee push-ups with whole body electromyostimulation. Br J Hosp Med 2016;77:542-3. 